УдК 94(74/79)

\title{
С.А. Шевченко
}

\section{РАЗВИТИЕ ДОРОЖНОЙ СИСТЕМЫ ШТАТА ВАШИНГТОН (1889-1913 гг.). ПРАВОВОЙ АСПЕКТ}

\begin{abstract}
Рассматривается процесс развития дорожной системы в штате Вашингтон в эпоху Прогрессивизма. Анализируется ряд законодательных актов, регулирующих дорожное строительство в штате. По мнению автора, определяющее влияние на изменение дорожной инфраструктуры оказала борьба между сторонниками сильной центральной власти штата и их противниками. Автор полагает, что централизация управления дорожной системой штата имела противоречивые последствия. Ключевые слова: США; Вашингтон; дорожная система; дороги; строительство.
\end{abstract}

Дорожная система штата Вашингтон на рубеже $\mathrm{XIX-XX} \mathrm{вв.} \mathrm{не} \mathrm{имела} \mathrm{единой} \mathrm{структуры} \mathrm{и} \mathrm{централи-}$ зованной системы управления, но находилась под юрисдикцией органов государственной власти разных уровней: федерального, штата, окружного и муниципального. Основываясь на правовых различиях существовавших форм собственности, следует указать, что в рассматриваемый период в дорожную систему штата входили: а) федеральные почтовые дороги; б) дороги штата; в) дороги округов; г) дороги городов, деревень и отдельных самоуправляемых административно-территориальных единиц (тауншипов); д) частные дорожные коммуникации. Каждому административному уровню соответствовали особая форма управления, а также исключительное право определения технологий дорожного развития (введение налогов, создание специальных финансовых фондов, привлечение рабочей силы к строительству). Таким образом, отдельный собственник, будь то частное лицо, государство или штат, управлял только принадлежащими ему дорожными объектами, и соответственно, либо имел очень ограниченные полномочия управления, либо не имел их вовсе на объектах чужой собственности.

Актуальность в современной дорожной системе определялась в Вашингтоне возрастающими темпами социального, экономического и индустриального развития. Если в 1890 г. население штата составляло 357 тыс. человек, то к 1910 г. оно увеличилось практически в три раза [1. Р. 33], что привело к стремительному развитию городов и деревень. В 1909 г. город Сиэтл впервые вошёл в число 50 крупнейших промышленных центров США [2. Р. 411]. За десять лет, с 1899 по 1909 г., число предприятий в штате возросло в полтора раза до 3,6 тыс., а число рабочих удвоилось до 80 тыс. человек [3. Р. 515; 4. Р. 207].

Развитие сельского хозяйства в этот период характеризуется непропорциональным распределением используемого земельного фонда и получаемой прибыли в восточной и западной частях штата. В восточных округах использовалось значительно большее количество земли для ведения фермерского хозяйства (от 20 до 60\%). Однако западные округа приносили несравнимо больший доход [2. Р. 309]. Причиной такой диспропорции являлось географическое расположение округов, которое способствовало или, наоборот, препятствовало развитию торговли. Западные округа примыкали к портовым районам, в которых продукция могла реализовываться круглогодично.
Доставку товаров из этих округов облегчало наличие расширенной коммуникационной системы - железных и общественных дорог. Восточные округа штата отделялись от западных труднопроходимым перевалом Каскадных гор и неразвитой инфраструктурой. Для восточно-вашингтонского производителя, таким образом, доступ в наиболее населённую часть штата и к Тихому океану был затруднён, поэтому он был вынужден сбывать свои товары на местных сельских ярмарках или пробиваться по бездорожью к железной дороге.

Сильный импульс экономическому и социальному прогрессу региона придало распространение автомобильного транспорта. Число зарегистрированных грузовых и легковых автомобилей к 1913 г. достигло 24 тыс. [5. Р. 279], к 1917 г. оно возросло более чем в три раза до 91337 единиц ${ }^{1}$. Популяризация автомобильного транспорта обнажила перед вашингтонской общественностью серьёзную проблему некачественных дорог [7. Р. 2], которые в эпоху индустриализации продолжали служить нуждам гужевого транспорта.

Несмотря на то что дороги в Вашингтоне строились ещё в территориальный период его истории, система транспортных коммуникаций региона была официально создана в 1889 г., при инкорпорировании Вашингтона в состав США. Периодизацию развития его дорожной системы в эпоху Прогрессивизма условно можно разделить на два этапа: во время первого (1889-1904 гг.) дорожное строительство находилось, главным образом, в ведении окружных советов; второй (1905-1913 гг.) наступил после создания Дорожного департамента и отличался интенсивным включением исполнительной власти штата в строительство коммуникационной системы.

На рубеже XIX-XX вв. в штате имелось более 40 тыс. км дорог, на строительство и обслуживание которых к тому моменту было потрачено около 1,5 млн долл. [8. Р. 259]. Однако следует отметить, что подавляющее количество дорожных километров являлось, по сути, проросшими дикой растительностью тропами не более 1,5 м шириной. Дорожное полотно по преимуществу было грунтовым и лишь около 7\% - покрыто щебнем [Ibid.]. Неудивительно, что распространённой проблемой того времени являлся сезонный характер транспортной системы [9]. Проезд по дорогам в большей части штата был затруднён весной и осенью, а зимой попросту невозможен [10. June 20. 1910]. Помимо этого, понятие «дорога» в изучаемый период времени не имело чётко установ- 
ленных правовых рамок и включало в себя широкий спектр полуофициальных коммуникаций. Отсутствие правовой регламентации, соответственно, создавало путаницу в определении формы собственности на конкретные дорожные участки, что отражалось на качестве дорожного строительства.

Решение насущной для штата проблемы началось с юридического оформления дорожной системы во время законодательных сессий легислатуры в 1889 [11. Ch. XIX. P. 733] и 1893 гг. [12. Ch. LXIX. P. 147]. Принятые на них акты узаконили проездные пути, использовавшиеся вашингтонской общественностью с 1882 г. Подавляющее количество дорог (не относящихся к федеральной или частной собственности) законы закрепили за округами и возложили ответственность за их улучшение на окружные советы [11. Ch. XIX, § 2, § 9. Р. 593, 596]. Для продуктивного решения дорожной проблемы округа были разделены на специальные дорожные районы пропорционально числу членов окружных советов, которым подчинялись специальные дорожные районные наблюдатели [Ibid. Ch. XIX, § 1-2. P. 618-619].

Для проведения дорожно-строительных работ, с 1889 по 1913 г. на местах взималось три вида налогов: a) ежегодный дорожный подушный налог, составлявший в разное время от 2 [Ibid. Ch. XIX, § 7. Р. 622] до 4 долл. [12. Ch. LXIX, § 6-7. Р. 151], который взимался с каждого мужчины в возрасте от 21 до 50 лет (кроме душевнобольных, пауперов и пожарных); б) ежегодный дорожный и мостовой налог, который поступал в одноимённый фонд каждого округа. Его размер в разные годы варьировался от 4 [11. Ch. XIX, $\S$ 14. Р. 623] до 7 миль [13. Сh. 151, § 1. Р. 476] (1 миля равнялась 0,1 цента) с каждого доллара, взимаемого с налогооблагаемой недвижимой собственности; в) районный налог, который собирался с жителей дорожных районов и аккумулировался в специальном фонде каждого района. Размер последнего устанавливался каждым округом отдельно, но в среднем составлял от 5 [12. Ch. LXIX, § 5. Р. 150] до 10 миль с доллара [13. Ch. 151, § 1. Р. 476].

Для улучшения и ремонта дорог окружные советы были уполномочены нанимать специальных рабочих [12. Ch. CXXIII, § 35. Р. 315], но из-за проблем с финансированием предоставление строительного тендера подрядчикам происходило довольно редко. Проблема нехватки рабочих рук решалась посредством привлечения к дорожным работам местных жителей, которых принятые законы обязывали выполнять работу в своём дорожном районе. Практика предусматривала ежегодную краткосрочную мобилизацию работоспособного сельского населения для строительства и улучшения дорожной сети, а также штрафы или взыскания за отказ от работы. За выполняемый труд жители районов получали поденную плату равную 2 долл. или 4 долл., если при работе задействовались их личные лошади, повозка, плуг и т.д. [Ibid. Ch. LXIX, § 12. P. 154].

Такая архаичная трудовая повинность была неэффективным методом решения дорожной проблемы. Во-первых, несмотря на обязательный характер, к работам приступало небольшое количество населения на недостаточный для прогрессивных результатов срок (обычно работы длились не болыше недели). Во-вторых, материально-техническое обеспечение такого строительства находилось на низком уровне. В-третьих, результатом работы являлось улучшение дорожного полотна небольшой протяжённости, пользу от которого получало ограниченное количество жителей дорожного района, главным образом проживающих недалеко от проездных путей. Строительство дорожного полотна в действительности означало уборку дорог, засыпку ям, а также сгребание земли к центральной части дороги с целью создать специальный «водосточный» уклон [14. Р. 146]. Более того, практика приводила к усилению социальных противоречий как между гражданами и окружными муниципалитетами, так и среди жителей дорожных районов. Трудовая повинность просуществовала в штате вплоть до 1901 г. [15. Ch. CXXXIII. Р. 273] и являлась главным препятствием для хорошей дорожной системы.

Жизнеспособность повинности объясняется медленным изменением отношения к характеру дорог у вашингтонской, в первую очередь сельской, общественности. На рубеже XIX-XX вв. такие факторы, как интенсивная индустриализация, развитие телеграфа и телефона, ускоренное распространение автомобильного транспорта, изменили консервативное сознание провинциальных вашингтонцев. Вступая в индустриальный мир, сельские жители начали представлять себе дороги не как нечто природное и неизменное, но как общественно-полезную собственность, которую может улучшать человек [14. Р. 146].

Логическим следствием наступающих когнитивных перемен стало формирование специфического настроения широких слоёв населения, которое лучше всего прослеживается сквозь призму тезиса, выдвинутого известным американским историком Робертом Уибе, получившем в его трудах название «поиск порядка» - стремление американской общественности к созданию стабильности в невиданных до того условиях индустриального хаоса [16]. Представленный «поиск» выражался в формировании общественного требования, в частности, создать хорошую дорожную систему в штате. Существующая трудовая повинность, которая оставалась в ведении муниципальных властей, не соответствовала поставленной задаче [17. P. 87]. Для строительства технологического дорожного полотна, пригодного для автотранспорта, были необходимы инновационные дорогостоящие методы. Это требовало привлечения крупных финансовых ассигнований, централизации органов управления, расширения аппарата исполнительной власти штата, формирования многочисленной рабочей силы и решительных кооперативных действий между властями округов и штата. Таким образом, общественное требование $^{2}$ о создании хороших дорог становится ключом к большой политической борьбе в легислатуре штата Вашингтон, апогеем которой стала законодательная сессия 1903 г.

Одним из вопросов, по которым развернулась ожесточённая борьба между депутатами, являлось создание центрального органа управления транспортной системой - Дорожного департамента. После про- 
должительных прений, соответствующий законопроект был одобрен дорожным комитетом и впоследствии принят обеими палатами. Однако губернатор штата Генри МакБрайд (1901-1905 гг.) наложил на него вето [21. Р. 488], усилив противоречия, возникшие между законодательной и исполнительной властью вокруг проблемы дорожного улучшения.

В 1905 г. при новой администрации, возглавляемой республиканцем Альбертом Мидом (19051909 гг.), губернаторское вето было преодолено законодателями. Согласно принятым законам [22. Ch. 7. Р. 18; Ch. 174. Р. 355] был создан Дорожный департамент штата Вашингтон (ДДШВ), во главе которого был поставлен дорожный комиссар, назначаемый губернатором на четыре года [22. Ch. 174. Р. 355; 23. Ch. 149, § 1. Р. 294]. Вместе с ним был учреждён Дорожный совет штата (ДСШ), в который входили ревизор штата, казначей и дорожный комиссар [22. Ch. 7, § 2. Р. 18]. Последний занимался разработкой планов дорожного строительства, а их утверждение возлагалось на ДСШ [22. Р. 18-19; 23. Ch. 149, § 4. Р. 295]. Созданный Совет также принимал решения о финансировании дорожного строительства [22. Ch. 7, § 4. Р. 18-19]. Необходимые средства, гарантирующие экономическое участие штата в улучшении коммуникаций, обеспечивались новым налогом, поступающим в созданный в том же году Фонд общественных дорог (ФОД) (англ. public highway fund) [Ibid. Ch. 137. Р. 253]. В разное время этот налог составлял от 0,25 [Ibid. § 2. Р. 252] (или 0,025 цента) до 1,25 мили [13. Ch. 64, § 1. Р. 220] с каждого доллара всей налогооблагаемой недвижимой собственности в штате.

Принятые в 1905 г. законы серьёзно расширили права исполнительной власти штата в дорожном строительстве. Они позволили принимать участие в улучшении муниципальной инфраструктуры, а также развивать собственную систему дорог штата. Её истоки были обозначены легислатурой ещё в 1893 г. принятием закона о строительстве первой гужевой дороги (англ. state wagon road) через Каскадные горы [12. Ch. CXXVI. P. 403]. Однако запланированное строительство, в конечном итоге, превратилось в местечковое улучшение дорожных участков, вследствие того, что проведение работ было поручено муниципальным властям нескольких округов, а также из-за выделения недостаточного количества средств - 20 тыс. долл. [Ibid. P. 405].

Развитие дорог штата вплоть до 1907 г. было практически спонтанным процессом. Ссылаясь на позиции членов ДСШ, необходимо отметить, что проект был в основном экспериментальным: «Изначально был обозначен простой план ремонта коротких отрезков дороги без любой мысли о формировании большой системы шоссе» [7. Р. 3]. Однако в 1907 г. дорожная система штата структурируется законодательно. По принятому закону «Об открытии, строительстве и улучшении дорог» [23. Ch. 151, § 1. Р. 308] она классифицируется на дороги штата и дополнительные дороги. Первые строились в малонаселённых и гористых районах, их возведение финансировалось из средств Фонда общественных дорог. Дополнительные дороги представляли собой второстепенные, сезон- ные $^{3}$ коммуникации, построенные рядом с главными транспортными артериями. Стоимость затрат на их строительство распределялась между штатом и округами [23. Ch. 151, § 1. Р. 308]. Систему дорог штата на тот момент сформировали 18 сообщений с запланированной протяжённостью около 4 тыс. км [23. Ch. 151, § 3-5. P. 309-313; 24. Ch. 61, § 1. P. 111-112; Ch. 92, $\S 2$. Р. 190; 25. December 30]. Ассигнования на их строительство с 1907 по 1911 г. составили чуть более 1 млн долл., на строительство дополнительных дорог и дорог округов было выделено около 6,3 млн долл. со стороны окружных советов [25. January 9].

Принятый в 1907 г. закон привёл к неожиданно отрицательным последствиям. Создание дополнительных дорог штата требовало серьёзных ассигнований со стороны окружных властей, которые начали выделять для этой цели средства, предназначенные для развития окружной дорожной системы [9]. Данная практика привела к негативной реакции со стороны сельской общественности, поскольку в некоторых округах «фермеры не получали на строительство подъездных путей к своим участкам и четверти от того, что платили в дорожные районные фонды» [26. December 22].

Уделяя внимание постоянной структуре дорожного полотна, ДДШВ решал проблему улучшения коммуникаций штата интенсивным путём, что предполагало проведение качественных строительных работ на относительно небольших участках дороги (до 15 км) [Ibid. April 13]. В округах проблема дорожного улучшения решалась экстенсивным путём, за счёт строительства сезонного дорожного полотна большой протяжённости, которое, однако, ежегодно приходилось ремонтировать [Ibid. December 23]. Вследствие этих факторов, выделенных со стороны окружных советов средств (6,3 млн долл.) не хватило для реализации поставленных задач.

С приходом к власти республиканца Мэриона Хэя (1909-1913 гг.) [7. Р. 3], вектор дорожной политики штата был изменен. В 1911 году легислатурой был принят очередной дорожный закон, по которому штат отказывался от строительства сезонных коммуникаций и преобразовал дополнительные дороги в постоянные шоссе. С целью ослабить давление на провинциальные бюджеты и увеличить влияние исполнительных органов власти штата в муниципальном дорожном строительстве, был создан ещё один специальный Фонд постоянных шоссе (ФПШ), который пополнялся за счёт обложения населения новым налогом в размере одной мили с каждого налогооблагаемого доллара. Разработанная дорожная программа сулила более сбалансированную финансовую политику. Однако в конце законодательной сессии 1911 г. легислатурой не был принят транспортный бюджет, вследствие фракционных разногласий в республиканской партии, а также из-за отсутствия единой позиции между палатами о первоочерёдности дорожного строительства и размере планируемых ассигнований [27. Р. 622-623, 773-774]. Вследствие того, что закон о транспортном бюджете не был принят, строительство дорог штата фактически приостановилось на два года ${ }^{4}$. 
Ряд коррективов в расклад сил на политической арене штата внёс 1912 г. На выборах губернатора сенсационную победу с разницей в 600 голосов одержал демократ Эрнест Листер (1913-1919 гг.). По результатам выборов в легислатуру штата, республиканцы потеряли абсолютное большинство в нижней палате, а также серьёзно уступили демократам и прогрессистам в Сенате. Новая администрация, соответствуя озвученным ранее предвыборным обещаниям [29. January 15. 1913], приступила к ревизии дорожного законодательства. Весной 1913 г. легислатурой был принят закон «О классификации общественных шоссе» [13. Ch. 65, § 1. Р. 221], который разделил имеющиеся в штате коммуникации на федеральные, окружные, частные дороги и шоссе штата. Последние были сформированы на основе дорог штата и постоянных шоссе и подразделялись, соответственно, на первичные и вторичные.

В качестве первичных шоссе были утверждены семь главных магистралей:

a) шоссе Пасифик (англ. pacific highway) - 412,5 км;

б) шоссе Сансет (англ. sunset highway) - 447 км;

в) шоссе Инланд Эмпайр (англ. inland empire highway) - 232,5 км;

г) шоссе Сентрал Вашингтон (англ. central washington highway) - 202,5 км;

д) шоссе МакКлеллан Пасс (англ. mcclellan pass highway) - 400,5 км;

е) шоссе Нэшнл Парк (англ. national park highway) - 231 км;

ж) шоссе Олимпик (англ. olympic highway) - 744 км.

Bсе остальные транспортные артерии, открытые после принятия этого акта, должны были входить в состав вторичных шоссе [Ibid. Ch. 66, § 1-6. Р. 221224]. Согласно новому закону строительство и ремонт первичных шоссе финансировались из двух дорожных фондов - ФПШ и ФОД. Вторичные шоссе штата улучшались по преимуществу из средств Фонда общественных дорог. Развитием муниципальной инфраструктуры продолжали заниматься окружные советы. Для выполнения задач по строительству и ремонту дорожной системы, на 1913-1915 гг. из обоих фондов было выделено около 5 млн долл. [13. Ch. 63, § 1. Р. 218; Ch. 76, § 1. Р. 250], что в три раза превысило сумму, ассигнованную штатом на дорожное строительство с 1905 по 1913 г.

Таким образом, дорожная система штата Вашингтон была официально создана в 1889-1893 гг. Вплоть до начала XX в. значительная часть дорог находилась в собственности округов. Этот период развития дорожной системы характеризовался рядом серьёзных проблем: децентрализацией дорожной политики; недостаточным финансированием; наличием дорожной трудовой повинности, препятствующей строительству хорошей дорожной сети; контрастом между прогрессивным развитием дорожной системы в западной части штата и отсталым - в восточной; отсутствием качественного дорожного покрытия. Неразвитая дорожная система продолжала ориентироваться на потребности гужевого транспорта и не могла отвечать запросам, предъявляемым эпохой индустриализации.

Создание Дорожного департамента штата, осуществлённое в 1905 г. в результате ожесточённой политической борьбы в легислатуре, имело противоречивые последствия. С одной стороны, дорожное строительство получило серьёзный экономический импульс в виде новых налоговых поступлений, что отразилось на увеличении количества построенных и улучшенных дорог. Если в последние два десятилетия XIX в. общий объём ассигнований на дорожное улучшение составил около 1,5 млн долл., то с 19051913 гг. он достиг 7,5 млн долл. Количество построенных дорожных километров возросло на 3,6 тыс. самый большой показатель за всю предыдущую историю штата. Протяжённость дорог с улучшенным покрытием увеличилась с 7 до 13,2\% [30. Р. 117].

С другой стороны, усиление позиций центральной власти в дорожной политике не решило некоторых насущных проблем. Рост ассигнований на дорожное строительство лишь повысил политизацию вопроса, что отразилось на расширении противоречий между политическими партиями, внутрипартийными фракциями, нижней и верхней палатой легислатуры, и, наконец, между законодательной и исполнительной ветвями власти. Создание ДДШВ не нормализовало диалог между органами власти штата и окружными муниципалитетами, но, наоборот, привело к экономическому давлению на провинциальные бюджеты со стороны штата, правовым осложнениям, выразившимся в законодательной чехарде и усилению коррупции. Наконец, не была решена проблема непропорционального развития дорожной системы в западной и восточной частях штата. Проведение дорожной политики в рассматриваемый период было ориентировано на улучшение коммуникационной системы в западных округах Вашингтона. Здесь, в среднем, более $20 \%$ дорог получили твёрдое всесезонное покрытие к 1911 г., в то время как в восточной части этот показатель едва превышал $2 \%$, а в одиннадцати восточных округах за эти годы не было улучшено ни одного метра дороги [Ibid. P. 38].

Тем не менее прогрессивный характер развития дорожного законодательства штата на рубеже XIX$\mathrm{XX}$ вв. послужил началом кардинального изменения всей дорожно-транспортной системы Вашингтона, с 1913 г. начавшей обретать тот облик, который имеет по сей день.

\section{ПРИМЕЧАНИЯ}

\footnotetext{
${ }^{1}$ Показатели не включают 6320 мотоциклов [6. Р. 303].

2 Общественную позицию по проблеме некачественных дорог в данный период времени представляли две национальные неправительственные организации: «Лига за хорошие дороги» и «Национальная ассоциация Хорошие дороги». Созданные на рубеже веков для популяризации автотранспорта и привлечения общественного внимания к проблеме дорожного улучшения, организации постепенно трансформировались в серьёзную политическую силу, повлиявшую на принятие политических решений в области дорожного законодательства на национальном и региональном уровнях (по этой проблеме см.: [18-20]).

${ }^{3}$ Сезонные дороги имели грунтовую поверхность и не имели водосточных дренажных систем.

${ }^{4}$ Следует сказать, что легислатура выделила 94 тыс. долл. на погашение задолженности перед подрядчиками [28. Ch. 93, § 1. Р. 427].
} 


\section{ЛИТЕРАТУРА}

1. Statistical Abstract of the United States. Forty-Third Number, 1920 // Prepared by the Bureau of Foreign and Domestic Commerce, under the Direction of the R.S. MacElwee. Washington : Government Printing Office, 1921.

2. Statistical Atlas of the United States // Prepared under the Supervision of Ch.S. Sloane. Washington : Government Printing Office, 1914.

3. Statistical Abstract of the United States. Twenty-Ninth Number, 1906 // Prepared by the Bureau of Statistics, under the Direction of the O.P. Austin. Washington : Government Printing Office, 1907.

4. Statistical Abstract of the United States. Thirty-Fourth Number, 1911 // Prepared by the Bureau of Statistics, under the Direction of the O. P. Austin. Washington : Government Printing Office, 1912.

5. Statistical Abstract of the United States. Thirty-Ninth Number, 1916 // Prepared by the Bureau of Foreign and Domestic Commerce, under the Direction of the E.E. Pratt. Washington : Government Printing Office, 1917.

6. Statistical Abstract of the United States. Forty-First Number, 1918 // Prepared by the Bureau of Foreign and Domestic Commerce, under the Direction of the B.S. Cutler. Washington: Government Printing Office, 1919.

7. Washington Secretary of State. State Archives. Governor Ernest Lister. Subject Files. Box № 57. Folder: Highway Commission 2, 1916. State Highway Construction in Washington.

8. Statistical Abstract of the United States. Thirty-Third Number, 1910 // Prepared by the Bureau of Statistics, under the Direction of the O.P. Austin. Washington : Government Printing Office, 1911.

9. Washington Secretary of State. State Archives. Governor Ernest Lister. Subject Files. Box № 57. Folder : Highway commission, 1915. State roads in Washington.

10. Washington Secretary of State. State Archives. Department of Highways. Administration, Central Files. Subject Files. Box № 7. Folder : State road camp № 5 Carrollton, 1909-1910.

11. Session Laws of the State of Washington, Enacted by the First State Legislature, Session of 1889-1890 / Published by Authority. Olympia : O.C. White, State Printer, 1890.

12. Session Laws of the State of Washington, Session of 1893 / Compiled by J. Price. Olympia : O.C. White, State Printer, 1893.

13. Session Laws of the State of Washington, Thirteenth Session, 1913 / Compiled by I. M. Howell. Olympia : Frank M. Lamborn, Public Printer, 1913.

14. Wells Ch. The Changing Nature of Country Roads: Farmers, Reformers, and the Shifting Uses of Rural Space, 1880-1905 // Agricultural History. 2006. Vol. 80, № 2 .

15. Session Laws of the State of Washington, Seventh Session, 1901 / Compiled by S. Nichols. Olympia : Gwin Hicks, State Printer, 1901

16. Wiebe R. The Search for Order, 1877-1920. N.Y. : Macmillan, 1967.

17. Lichtenstein A. Good Roads and Chain Gangs in the Progressive South: "The Negro Convict is a Slave" // The Journal of Southern History. 1993. Vol. 59, № 1. P. 85-110.

18. Carothers J. Good roads and how to obtain them. N.Y. : Publ. by T.B. Ventres, 1898.

19. Davis Ch. National Highways to Bring about Good Roads Everywhere. Washington D.C. : publ. by National Highway Assotiation, 1913.

20. Fuller W. Good Roads and Rural Free Delivery of Mail // The Mississippi Valley Historical Review. Vol. 42, № 1. January 1955. P. 67-83.

21. Session Laws of the State of Washington, Eight Session, 1903 / Compiled by S. Nichols. Olympia : Allen \& Lamborn Printing Company, 1903.

22. Session Laws of the State of Washington, Ninth Session, 1905 / Compiled by S. Nichols. Olympia : C.W. Gorham, Public Printer, 1905.

23. Session Laws of the State of Washington, Tenth Session, 1907 / Compiled by S. Nichols. Olympia : C.W. Gorham, Public Printer, 1907.

24. Session Laws of the State of Washington, Eleventh Session, 1909 / Compiled by S. Nichols. Olympia : E.L. Boardman, Public Printer, 1909.

25. Washington Secretary of State. State Archives. Governor Marion Hay. Subject Files. Box № 16. Folder : Highway commission, 1911.

26. Washington Secretary of State. State Archives. Governor Marion Hay. Subject Files. Box № 16. Folder : Highway commission, 1910.

27. House Journal of the Twelfth Legislature of the State of Washington, Begun and Held at Olympia, State Capital, 1911 / Compiled by L. Grinstead. Olympia: E.L. Boardman, Public Printer, 1911.

28. Session Laws of the State of Washington, Twelfth Session, 1911 / Compiled by I.M. Howell. Olympia : E.L. Boardman, Public Printer, 1911.

29. Washington Secretary of State. State Archives. Governor Ernest Lister. Subject Files. Box № 81. Folder : Penitentiary - Honor Camps, 19131914.

30. Pennybacker J. Mileage and Cost of Public Roads in the United States in 1909. Washington D.C. : Government printing office, 1912.

Статья представлена научной редакцией «История» 9 октября 2017 г.

ROAD SYSTEM DEVELOPMENT IN THE STATE OF WASHINGTON (1889-1913). THE LEGAL ASPECT Vestnik Tomskogo gosudarstvennogo universiteta - Tomsk State University Journal, 2018, 426, 211-216. DOI: $10.17223 / 15617793 / 426 / 25$

Sergey A. Shevchenko, Tomsk State University (Tomsk, Russian Federation). E-mail: Shevchenkovskrs@yandex.ru Keywords: USA; Washington; road system; roads; building.

The article covers the road system development in the State of Washington in the Progressive Era. The article is based on the sources from the Washington State archives and a wide range of legislative acts adopted by the State Legislature during the period under review. Description of the state road system at the end of the 19th century is specified in the article. Certain typical issues of the state road system of that time are revealed: the absence of legal regulation, insufficient financing, construction of seasonal roadway designed for cartage transport, disproportionate development of roads in the western and eastern parts of the State, general technological backwardness. The article explains the necessity for the creation of a new all-season road system at the beginning of the 20th century and points out economic prerequisites for the construction of new roads in Washington. The article shows the conditional periodization of the state road system in the Progressive Era, which is divided into two stages: decentralized (1889-1904) and centralized (1905-1913). The main part of the article gives a detailed analysis of the legislative acts governing the development of the state road system. In particular, the following issues are considered: areas of legal and economic responsibility of municipal and state authorities; state tax policy and road construction financing procedure; applying and abolition of the so-called "public road service" practice and its impact on the development of roads in the State; political debates in the State Legislature in 1903 on the problem of the State Road Department establishment; road system management at the municipal and state levels, activities of the State Road Department and the State Highway Council; reasons of the Republican Administrations' road policy failure in 1907 and 1911. The article concludes that the road management system in Washington progressively developed from decentralized to centralized. In general, this process was progressive and led to the creation of the State highway system and construction of a large number of roads. However, at the same time centralization of the road construction had some negative consequences, such as expansion of political contradictions in the Washington State Legislature, economic pressure on municipal budgets by the State authorities, legal complica- 
tions and the so-called "legislative leapfrog", increased corruption, unresolved problems of disproportionate development of the road system in the eastern and western parts of the State.

\section{REFERENCES}

1. Bureau of Foreign and Domestic Commerce, under the Direction of R.S. MacElwee. (1920) Statistical Abstract of the United States. Forty-Third Number, 1920. Washington: Government Printing Office.

2. Under the Supervision of Ch.S. Sloane. (1914) Statistical Atlas of the United States. Washington: Government Printing Office.

3. Bureau of Statistics, under the Direction of O.P. Austin. (1907) Statistical Abstract of the United States. Twenty-Ninth Number, 1906. Washington: Government Printing Office.

4. Bureau of Statistics, under the Direction of O.P. Austin. (1912) Statistical Abstract of the United States. Thirty-Fourth Number, 1911. Washington: Government Printing Office.

5. Bureau of Foreign and Domestic Commerce, under the Direction of E.E. Pratt (1917) Statistical Abstract of the United States. Thirty-Ninth Number, 1916. Washington: Government Printing Office.

6. Bureau of Foreign and Domestic Commerce, under the Direction of B.S. Cutler. (1919) Statistical Abstract of the United States. Forty-First Number, 1918. Washington: Government Printing Office.

7. Washington Secretary of State. State Archives. Governor Ernest Lister. Subject Files. Box 57. Folder: Highway Commission 2, 1916. State Highway Construction in Washington.

8. Bureau of Statistics, under the Direction of O.P. Austin. (1911) Statistical Abstract of the United States. Thirty-Third Number, 1910. Washington: Government Printing Office.

9. Washington Secretary of State. State Archives. Governor Ernest Lister. Subject Files. Box 57. Folder: Highway commission, 1915. State roads in Washington.

10. Washington Secretary of State. State Archives. Department of Highways. Administration, Central Files. Subject Files. Box 7. Folder: State Road Camp no. 5 Carrollton, 1909-1910.

11. Authority. (1890) Session Laws of the State of Washington, Enacted by the First State Legislature, Session of 1889-1890. Olympia: O.C. White, State Printer.

12. Price, J. (1893) Session Laws of the State of Washington, Session of 1893. Olympia: O.C. White, State Printer.

13. Howell, I.M. (1913) Session Laws of the State of Washington, Thirteenth Session, 1913. Olympia: Frank M. Lamborn, Public Printer.

14. Wells, Ch. (2006) The Changing Nature of Country Roads: Farmers, Reformers, and the Shifting Uses of Rural Space, 1880-1905. Agricultural History. 80:2.

15. Nichols, S. (1901) Session Laws of the State of Washington, Seventh Session, 1901. Olympia: Gwin Hicks, State Printer.

16. Wiebe, R. (1967) The Search for Order, 1877-1920. N.Y.: Macmillan.

17. Lichtenstein, A. (1993) Good Roads and Chain Gangs in the Progressive South: "The Negro Convict is a Slave". The Journal of Southern History. 59:1. pp. $85-110$.

18. Carothers, J. (1898) Good roads and how to obtain them. N.Y.: Publ. by T.B. Ventres.

19. Davis, Ch. (1913) National Highways to Bring about Good Roads Everywhere. Washington, D.C.: publ. by National Highway Assotiation.

20. Fuller, W. (1955) Good Roads and Rural Free Delivery of Mail. The Mississippi Valley Historical Review. 42:1. January. pp. 67-83.

21. Nichols, S. (1903) Session Laws of the State of Washington, Eight Session, 1903. Olympia: Allen \& Lamborn Printing Company.

22. Nichols, S. (1905) Session Laws of the State of Washington, Ninth Session, 1905. Olympia: C.W. Gorham, Public Printer.

23. Nichols, S. (1907) Session Laws of the State of Washington, Tenth Session, 1907. Olympia: C.W. Gorham, Public Printer.

24. Nichols, S. (1909) Session Laws of the State of Washington, Eleventh Session, 1909. Olympia: E.L. Boardman, Public Printer.

25. Washington Secretary of State. State Archives. Governor Marion Hay. Subject Files. Box 16. Folder: Highway commission, 1911.

26. Washington Secretary of State. State Archives. Governor Marion Hay. Subject Files. Box 16. Folder: Highway commission, 1910.

27. Grinstead, L. (1911)House Journal of the Twelfth Legislature of the State of Washington, Begun and Held at Olympia, State Capital, 1911. Olympia: E.L. Boardman, Public Printer.

28. Howell, I.M. (1911) Session Laws of the State of Washington, Twelfth Session, 1911. Olympia: E.L. Boardman, Public Printer.

29. Washington Secretary of State. State Archives. Governor Ernest Lister. Subject Files. Box 81. Folder: Penitentiary - Honor Camps, $1913-1914$.

30. Pennybacker, J. (1912) Mileage and Cost of Public Roads in the United States in 1909. Washington, D.C.: Government Printing Office.

Received: 09 October 2017 